Dokuz Eylül Üniversitesi-Mühendislik Fakültesi

Fen ve Mühendislik Dergisi

Cilt 19, Sayı 56, Mayıs 2017
Dokuz Eylul University-Faculty of Engineering Journal of Science and Engineering Volume 19, Issue 56, May 2017

DOI: $10.21205 /$ deufmd.2017195661

\title{
Fononik Kristal Kaplama ile Gösteri Salonlarında Akustik Yalıtımın Sayısal İncelenmesi
}

\author{
Nurettin KÖRÖZLÜ̈1 \\ ${ }^{1}$ Mehmet Akif Ersoy Üniversitesi, Fen Edebiyat Fakültesi, Nanobilim ve Nanoteknoloji \\ Bölümü, 15030, Burdur
}

(Alınıș / Received: 17.08.2016, Kabul / Accepted: 07.04.2017, Online Yayınlanma / Published Online: 02.05.2017)

Anahtar Kelimeler Özet: Periyodik üçgensel ahşap çıkıntılardan oluşan fononik Akustik yalıtım, Fononik kristal, Yüzey kipi, Sonlu Elemanlar Yöntemi kristal ile duvarların kaplanmasının ses yalıtımına katkı sağlayacağı sayısal hesaplarla gösterilmiştir. Ses yalıtımı fononik kristalin yüzey kipleri ile gerçekleştirilmektedir. Sonlu Elemanlar Yöntemi ile yürütülen band yapısı hesapları fononik kristal periyodu $25 \mathrm{~cm}$, ahşap et kalınlığı $15 \mathrm{~mm}$ ve üçgen tepe açısı 60 derece iken tepe frekansı $553 \mathrm{~Hz}$ olan yüzey bandını göstermektedir. Yüzey kiplerinin üçgenler arasındaki düzlüklerde yerelleştiği yüzey bandı $440 \mathrm{~Hz}$ frekansındaki akort notasını kapsamaktadır. Durağan Sonlu Elemanlar analizleri yaklaşık olarak $300 \mathrm{~Hz}$ ile $550 \mathrm{~Hz}$ arasında yüzey ile küçük açllar yaparak gelen düzlem dalgaların az yansıma ile ve saçılmadan yüzeyde kılavuzlanabildiğini göstermiştir. Kılavuzlama $440 \mathrm{~Hz}$ frekansında 30 dereceye kadar olan geliş açılarında sağlanabilmektedir.

\section{Numerical Investigation of Acoustic Isolation in Performance Halls through Covering with Phononic Crystals}

\begin{abstract}
Keywords
Acoustic isolation, Phononic crystal, surface mode, Finite Element Method

Abstract: Sound isolation via covering walls with phononic crystal composed of periodic triangular wooden protrusions is demonstrated through numerical calculations. Sound isolation is achieved by surface modes of the phononic crystal. Band structure calculations through the Finite Element Method revealed a surface band with a maximum of $553 \mathrm{~Hz}$ when the periodicity, wall thickness and triangle apex angle are $25 \mathrm{~cm}, 15 \mathrm{~mm}$ and 60 degrees, respectively. Surface band the modes of which are localized in the flat regions between triangles covers the accord frequency at $440 \mathrm{~Hz}$. Stationary Finite Element analyses demonstrate that plane waves with frequency between approximately $300 \mathrm{~Hz}$ and $550 \mathrm{~Hz}$ incident at small angles with the surface can be guided over the surface with low reflection and scattering. Guiding at $440 \mathrm{~Hz}$ can be achieved up to 30 degrees angle of incidence.
\end{abstract}

*Sorumlu yazar: nkorozlu@mehmetakif.edu.tr 


\section{Giriş}

Konser salonu ve tiyatro salonu gibi ortamlarda ses yalıtımı büyük önem taşımaktadır [1]. Ses yalıtımı denilince ilk akla gelen malzemeler arasında fononik kristallerde yer alır. Fononik kristal yoğunluk ve ses hızı gibi akustik özellikleri bir, iki veya üç boyutta periyodik değișen yapay malzemelerdir [2]. Fononik kristaller ile ses yalıtımı akustik dalgaların kristal boyunca iletilmeyip yansitıldığı frekans aralıklarını ifade eden band aralıkları sayesinde gerçekleștirilmektedir [3-6]. Band aralığ özelliği sayesinde duyulabilir ses bölgesinde ağaçların periyodik dizilimi ile yerleşim yerlerinde çevresel gürültünün azaltılması sağlanmaktadır [7]. Ayrıca katı arka planda periyodik katı ya da sıvı saçıcılardan oluşan fononik kristaller ile ultrases frekanslarında yalıtım da gösterilmiştir [8, 9]. Son yıllarda radyo frekanslı uygulamalar için gigahertz mertebesinde frekanslarda band aralığ sergileyen hipersonik fononik kristaller üzerine çalışmalar da yapılmaya başlanmıştır [10, 11]. Ayrıca güncel uygulamalardan biri de Silisyum ve Germanyum gibi yariletken malzemelerde periyodik modülasyon ile akustik fononlar için band aralığı oluşturarak malzemenin isıl iletkenliğinin düşürüldüğü termokristaller olarak adlandırılan yapılardır [12-14].

Fononik kristallerde periyodikliğin bozulması ile de önemli uygulamalar elde edilebilmektedir. Örneğin iki boyutlu bir fononik kristalde saçıcılardan bir sıra uzaklaștırıldığında oluşan boşlukta akustik dalgaların kılavuzlanması sağlanmaktadır $\quad[6, \quad 15-18]$. Ayrıca fononik kristal dalga kılavuzlarının dik açılı keskin bükümlerinde az kayıplı iletim sağlandığından bu tür yapılarda karmaşı yörüngelerde akustik dalga iletimi de gösterilmiştir [19]. Sayılan bu özellikler fononik kristal band aralığında çizgisel kusur nedeniyle ortaya çıkan kusur durumları sayesinde elde edilmektedir. Çizgisel kusurların yanı sıra fononik kristalde yalnızca bir saçıcının uzaklaştırılması ya da geometrik ve/veya malzeme özelliklerinin değiștirilmesi ile nokta kusurlar da elde edilebilmektedir [20, 21].

Fononik kristal band aralığında yerelleşmiş kip türlerinden biri de sonlu ölçülerdeki fononik kristal ile çevreleyen ortam arakesitinde ortaya çlkan yüzey kipleridir. Fononik kristal yüzey kipleri ilk olarak Zhao vd. tarafından hava ortamında periyodik çelik çubuklardan oluşan yapı için süper hücre hesapları ile sayısal olarak gösterilmiştir [22]. Daha sonra Jia vd. su ortamında çelik çubuklardan oluşan fononik kristal için megahertz mertebesindeki frekanslarda yüzey dalgalarının düzlemsel dalgalarla ve noktasal kaynakla uyarılmasını deneysel olarak göstermiştir [23]. Çiçek vd. ise hava ortamında kare örgü düzeninde dizili iki boyutlu fononik kristalde yüzey kiplerinin havadan gelen düzlem dalgalarla uyarılma ve kılavuzlanma özelliklerini deneysel olarak incelemiştir [24]. Çiçek vd. ayrıca sonlu boyuttaki fononik kristalin köşesine bir saçıcı yerleştirerek uyarılan yüzey dalgalarının 90 derecelik keskin bükümler boyunca az kayıpla iletilebildiğini göstermiştir [25]. Bunun yanı sıra iki fononik kristal yüzeyi birbirlerine yaklaștırıldığında frekansa ve aradaki mesafeye bağlı olarak fononik kristallerin birinde uyarılan yüzey modu diğerine atlayabilmektedir. $\mathrm{Bu}$ iki fononik kristal yüzeyinin çıkışlarındaki akustik alan ölçülerek değişik algılayıcılar yapılabilir. Örneğin Doppler etkisinden yararlanılarak ultrasonik frekanslarda hız ölçümü önerilmiștir [26]. Ayrıca birbirine komşu bir çizgisel kılavuz ve yüzey arasında kip geçişleri göz önünde bulundurularak da benzer algılayıcılar öngörülmüştür [27]. 
Yukarıda bahsedildiği gibi fononik kristal yüzey kiplerinde akustik enerji yüzeye örgü sabiti mertebesinde bir ölçekte yerelleștiğinden bu kiplerin düz yüzeylerden akustik dalgaların yansımasının ya da saçılmasının önlenmesinde kullanılması öngörülebilir.

Bu çalıșmada gösteri salonları gibi kapalı ortamların duvarlarindan ses yansitıcılığının ve saçılmasının azaltılması için fononik kristallerin kullanımının etkisi üzerinde durulmuştur. Pratik uygulamalar da göz önünde bulundurularak fononik kristal tasarımında bir beton duvar üzerinde bir boyutta periyodik ahşap çıkıntılar incelenmiştir. Çıkıntıların periyodu ve et kalınlığı gibi geometrik parametrelerine bağlı optimizasyon yapılarak $100 \mathrm{~Hz}$ mertebesindeki düşük frekanslar için ses yalıtımı incelenmiştir. Yalıtım fononik kristalin yüzey kiplerinin uyarılıp duvara yakın yerelleşerek kılavuzlanmaları ile sağlanmaktadır. Fononik kristallerin yüzey kiplerinin eldesi ve ses yalıtım özelliklerinin incelenmesinde Sonlu Elemanlar Yönteminden yararlanılmıştır. $\mathrm{Bu}$ çalışma gösteri salonları gibi ortamlarda ses yalıtımının fononik

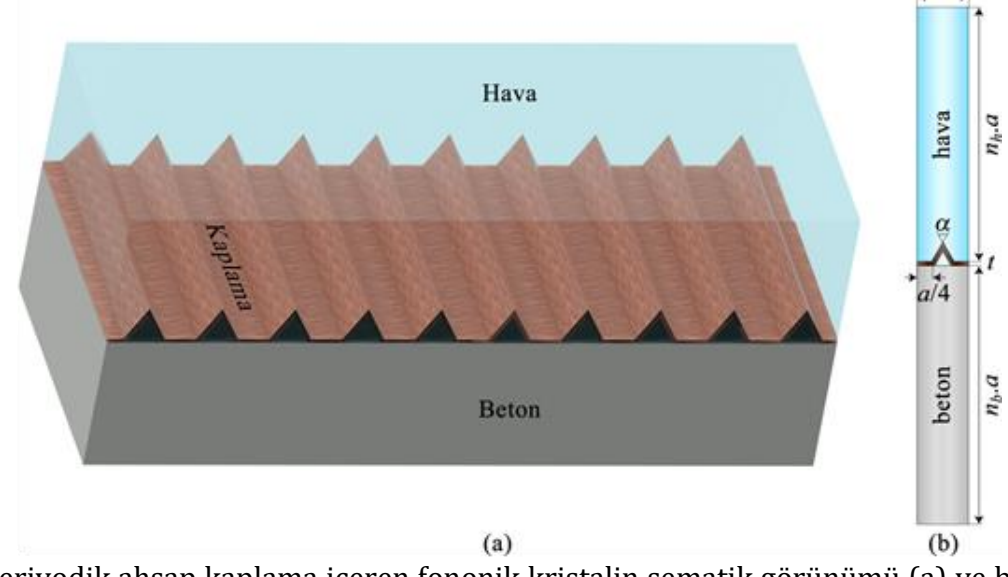

Şekil 1. Periyodik ahşap kaplama içeren fononik kristalin şematik görünümü (a) ve band yapısı hesaplarında kullanılan birim hücre (b).

Bragg kırınımı göz önünde olması beklenir. Çalışmada uygun bulundurulduğunda örgü sabitinin sesin fononik kristal geometrik parametreleri dalga boyunun (örneğin $440 \mathrm{~Hz}$ için sonlu elemanlar yöntemine (Finite havada yaklaşı olarak $\lambda=78 \mathrm{~cm}$ ) kesri $\quad$ Element Method, FEM) dayalı band yapısı kristaller kullanılarak pratik biçimde sağlanmasına yönelik yapılacak uygulamalı çalışmalara rehber olacaktır.

\section{Materyal ve Metot}

Bu çalışmada incelenen yapı Şekil 1(a)'da görülmektedir. Burada hava içeren bir odadaki bir beton duvarın yüzeyi periyodik üçgensel çıkıntılar içeren ahşap kaplama ile kaplıdır. Bu kaplama beton yüzeyinde bir boyutlu fononik kristal oluşturmaktadır. Çıkıntıların altında kalan üçgensel bölge hava boşluğudur. Uygun periyodikliğin (örgü sabiti, $a$ ), ahşap kalınlığının ( $t$ ) ve üçgen tepe açısının $(\alpha)$ fonksiyonu olarak akort notası (ya da standart nota) olarak bilinen $f=440 \mathrm{~Hz}$ frekansındaki Re (ya da $\mathrm{A}_{4}$ ) notasını kaplayan $200-600 \mathrm{~Hz}$ aralığında ses dalgalarının fononik kristal ile kaplı olan ve olmayan duvardan yansıma özellikleri incelenmiștir. Fononik kristal ile kaplamanın beton duvar ile hava ara kesitinde akustik yüzey dalgalarını uyararak kılavuzlama sağlaması ve duvarın ses yansitıcilığını azaltması beklenmektedir [24]. 
hesapları ile belirlenmiştir. Hesaplar için Şekil 1(b)'de gösterilen 1 boyutlu birim hücre kullanılmıştır. Düzleme dik (z) eksenindeki süreklilikten dolayı bütün hesaplamalar iki boyutta yürütülmüştür. Burada periyodiklik $(x)$ eksenine dik sınırlar Floquet-Bloch periyodik sinır koșulları ile birbirine ilişsilendirilmiştir [24]. Bu koşullar altında $p(x, y)$ hava bölgesindeki akustik basınç alanı olmak üzere birim hücrenin sağ (R) ve sol (L) kenarları arasındaki ilişki

$$
p_{R}(x, y)=p_{L}(x, y) \cdot \mathrm{e}^{\mathrm{i} k_{x} a} \cdot \mathrm{e}^{\mathrm{i} k_{y} a}
$$

şeklinde yazllabilir [28]. Burada $k_{x}$ ve $k_{y}$ dalga vektörünün dik bileşenleridir. Band yapısı hesaplarında $k_{y}=0$ alınarak $k_{x}$ bileşeni 0 ile $\pi / a$ arasında değiştirilip fononik kristal yüzeyinin indirgenmiş band yapısı elde edilmiştir [24]. Şekil 1(b)'deki birim hücrede beton blok $n_{b}$, hava katmanı da $n_{h}$ örgü sabiti kalınlığındadır. Band yapısı hesaplarında Çizelge-1'de verilen $n_{b}=n_{h}=5$ değerlerinde yakınsama gözlenmiştir. $\mathrm{Bu}$ nedenle $\alpha$ tepe açısı için band yapısı hesaplarında bu değerler kullanılmıștır.

Tablo 1. FEM simülasyonlarında kullanılan geometrik ve fiziksel parametreler.

\begin{tabular}{ccc}
\hline \hline Parametre (Birim) & Açıklama & Değer \\
\hline$a(\mathrm{~cm})$ & Örgü sabiti & 25 \\
$t(\mathrm{~cm})$ & Ahşap kalınlığı & 1.5 \\
$\alpha\left(^{\circ}\right)$ & Tepe açısı & $60-90$ \\
$n_{b}$ & Katı birim hücre sayısı & 5 (band) -8 (simülasyon) \\
$n_{h}$ & Hava birim hücre sayısı & 5 (band) -3 (simülasyon) \\
$f(\mathrm{~Hz})$ & Frekans & $200-600$ \\
$\theta\left(^{\circ}\right)$ & Kaynak geliş açısı & $5-60$ \\
$c_{h}(\mathrm{~m} / \mathrm{s})$ & Havada ses hızı & $343^{\mathrm{a}}$ \\
$\rho_{h}\left(\mathrm{~kg} / \mathrm{m}^{3}\right)$ & Havanın yoğunluğu & $1.21^{\mathrm{a}}$ \\
$E_{b}(\mathrm{GPa})$ & Betonun Young modülü & $25^{\mathrm{b}}$ \\
$v_{b}$ & Betonun Poisson oranı & $0.33^{\mathrm{b}}$ \\
$\rho_{b}\left(\mathrm{~kg} / \mathrm{m}^{3}\right)$ & Betonun yoğunluğu & $2300^{\mathrm{b}}$ \\
$E_{c}(\mathrm{GPa})$ & Çamın Young modülü & $0.32^{\mathrm{b}}$ \\
$v_{\zeta}$ & Çamın Poisson oranı & $0.347^{\mathrm{b}}$ \\
$\rho_{c}\left(\mathrm{~kg} / \mathrm{m}^{3}\right)$ & Çamın yoğunluğu & $482^{\mathrm{b}}$
\end{tabular}

aÇiçek vd. [24], bCOMSOL MultiPhysics Malzeme Kütüphanesindeki ilgili referanslar.

FEM kullanılarak hem band yapısı hesaplarında hem de durağan simülasyonlarda Şekil 1(a) ve (b)'de görüldüğü gibi akışkan olan hava ortamı ve katı çam kaplama ve beton duvar bulunmaktadır. Hava ortamı yalnızca boyuna akustik dalgaları desteklerken, katı malzemelerde enine dalgaların uyarılması da söz konusu olmaktadır [29]. Bu nedenle hava ortamı için problemin çözümünde sadece boyuna dalgaları içeren aşağıdaki Helmholtz tipi diferansiyel denklemin çözümü aranmaktadır [29]:

$$
\Delta \cdot\left(\frac{1}{\rho_{h}} \Delta p(x, y)\right)+\frac{\omega^{2} p(x, y)}{\rho_{h} c_{h}^{2}}=0 ; \Omega_{\mathrm{h}} \text { üzerinde }
$$

Burada $\Omega_{h}$ hesaplama uzayının hava içeren akışkan kısmını ifade etmekte olup $\rho_{h}$ ve $c_{h}$ da sirasiyla havanın yoğunluğu ve havada ses hızıdır. Hesaplamalarda kullanılan değerler 
Tablo-1'de verilmiştir. Eşitlik (2)'de $\omega$ ise açısal frekanstır $(\omega=2 \pi f)$. Ayrıca Eşitlik (2)'de basınç alanının harmonik olduğu varsayllmıștır: $p(x, y, t)=p(x, y) \mathrm{e}^{-\mathrm{i} \omega t}$.

Hesaplamalarda katı bölgelerin formülasyonunda ise elastik dalga denkleminin çözümü aranmaktadır [29]:

$$
\nabla \sqsubset \boldsymbol{\sigma}=-\rho_{k} \omega^{2} \mathbf{u} ; \Omega_{\mathrm{k}} \text { üzerinde }
$$

$\mathrm{Bu}$ eşitlikte $\sigma$ ve u sırasıyla Cauchy gerilme tensörü ve katı içerisinde atomların yer değiștirme vektörüdür. Eşitlik (3)'te $\rho_{k}$ ise katının yoğunluğudur. Çam $\left(\rho_{\varsigma}\right)$ ve beton $\left(\rho_{b}\right)$ için yoğunluk değerleri Tablo-1'de verilmiștir. Eșitlik (3)'ün çözümü için gerekli diğer girdiler ise Young modülü $(E)$ ve Poisson oranından $(v)$ oluşan elastik sabitlerdir. Çam ve beton için çalışmada kullanılan Young modülü (sırasıyla $E_{c}$ ve $E_{b}$ ) ve Poisson oranı (sırasiyla $v_{c}$ ve $v_{b}$ ) değerleri Tablo-1'de verilmiştir. Son olarak, Eşitlik (3)'teki $\Omega_{\mathrm{k}}$ hesaplama uzayının katı bölgesini ifade etmektedir. FEM hesapları Eșitlik (2) ve (3)'ün bir arada çözüldüğü karıșı bir formülasyon içermektedir.

FEM modellerinde hava ve katı ortamların bir arada incelenmesi bu ortamların ara kesitinde sinır koşullarının doğru tanımlanmasını gerektirmektedir. Örneğin hava ortamındaki basınç değişimleri hemen yanındaki katı ortamında yüzey atomlarında yer değiştirmeye sebep olurken, katı ortamındaki elastik titreşimler de havada moleküllerin ivmelenmesini sağlamaktadır. $\mathrm{Bu}$ durumda sınır koşulları aşağıdaki gibi ifade edilir [29]:

$$
\begin{aligned}
& \mathbf{n}_{\mathbf{h}} \cdot\left(\frac{1}{\rho_{h}} \nabla p(x, y)\right)=a_{n} ; \Gamma_{h} \text { üzerinde } \\
& \mathbf{f}_{\mathbf{k}}=-\mathbf{n}_{\mathbf{k}} p(x, y) ; \Gamma_{k} \text { üzerinde }
\end{aligned}
$$

Eşitlik (4a)'nın sağındaki $\Gamma_{\mathrm{h}}$ arakesitine dik $a_{n}$ ivmelenmesi yukarıda belirtildiği gibi katı atomlarının yer değiştirmelerinin hava bölgesinde olușturduğu ivmelenmedir. Buna karșllık Eşitlik (4b)'de $p(x, y)$ basınç alanı katı atomları üzerinde yer değiştirmeye neden olan $\mathbf{f}_{\mathbf{k}}$ kuvvetini oluşturmaktadır. Eşitlik (4a) ve (4b)'de $n_{h}$ ve $n_{k}$ sirasiyla hava ve katı ortamlarından bakıldığında $\Gamma_{\mathrm{h}}$ ve $\Gamma_{\mathrm{k}}$ ara kesitlerine dik, ilgili arakesitten dışarı doğru yönelmiş birim vektörlerdir.

Band yapısı hesaplarından frekans dağılımı ve kip profilleri elde edilen bir boyutlu fononik kristalin duvarın yansıtıcılığına etkisi iki boyutlu durağan FEM analizleri ile incelenmiştir. FEM analizlerinde Şekil 2'deki gibi hesaplama uzayı göz önünde bulundurulmuștur. Şekil 2'de hesaplama uzayının sol kenarındaki yamuk şekilli bölge akustik kaynağı tanımlamak için kullanılmaktadır. Kaynağın genişliği $w_{s r c}$ olup eğik kenarı $\theta$ geliş açısına bağlı olarak tanımlanmaktadır. Hesaplama modelinde beton duvarın alt kenarı yer değiştirmenin (u) serbest bırakıldığı sınır koşulu ile tanımlanmıştır. Hesaplama uzayının hava sınırları ise uzayı terk eden akustik dalgaların yansımasını önleyecek şekilde az yansımalı sınır koşulu ile tanımlanmıştır. FEM simülasyonlarında $f$ ve $\theta$ değiştirilerek sadece beton ve fononik kristal ile kaplı duvardan sesin yansıma özellikleri incelenmiştir.

FEM band yapısı hesaplarında ve simülasyonlarında ahşap kısımlar diğer bileşenlere göre çok daha ince olduğundan uyarlamalı üçgensel kafes kullanılmıştır. Kafeslerde en büyük eleman boyutu ahşap kısımlar için $t / 4$, hava ve beton bölgeleri için $a / 2$ olarak alınmıştır. $\mathrm{Bu}$ durumda band yapısı hesaplarında süper hücrede toplam 13108 üçgensel eleman üretilirken minimum eleman kalitesi de 0.69 
olmaktadır. Durağan $\quad$ FEM simülasyollarında ise, toplam 221803 elemana karşılık minimum eleman kalitesi 0.49 olmaktadır. Bu değerlerin her iki durumda da yakınsama sağladı̆̆ gözlenmiştir.

\section{Bulgular}

Bir boyutlu fononik kristalin Şekil 1(b)'deki birim hücre kullanılarak FEM ile hesaplanan band yapısı Şekil 2(a)'da görülmektedir. Burada 'hava çizgisi', $\omega=c_{h} k_{x}$ ile ifade edilen havanın dağılım bağıntısına karşılık gelmektedir [24]. Bu çizgi üzerindeki 'hava kipleri' olarak ifade edilen taralı alan birim hücredeki hava ortamının çınlanım kipleri olup bunların yüzey kipleri ile ilgisi yoktur. Bu yüzden taralı bölgedeki kiplere yer verilmemiştir.

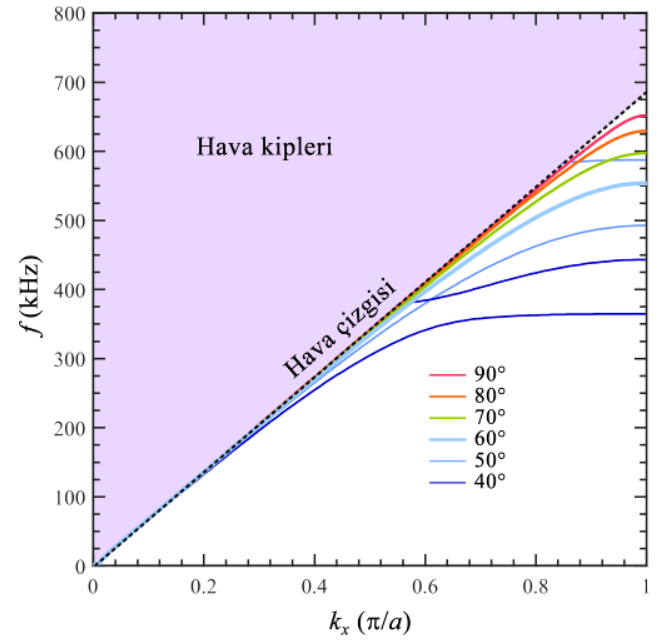

(a)

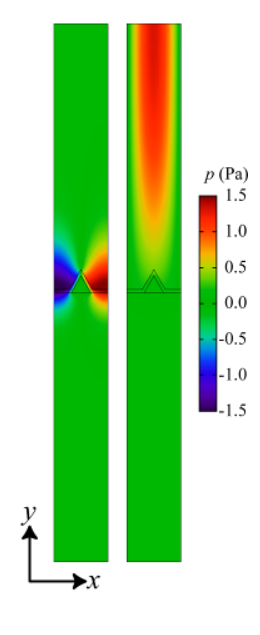

(b)

Şekil 2. Bir boyutlu fononik kristalin band yapısının tepe açısına ( $\alpha$ ) bağlı değișimi (a), $\alpha=60^{\circ}$ için $k_{x}=\pi / a$ noktasındaki en düşük frekanslı iki kipin profilleri (b).

Şekil 2(a)'da $a=25 \mathrm{~cm}$ ve $t=15 \mathrm{~mm}$ olan bir boyutlu fononik kristalin $\alpha$ tepe açısının $40^{\circ}$ ile $90^{\circ}$ arasında $10^{\circ}$ adımlarla taranması ile elde edilen yüzey bandları da görülmektedir. $\alpha=90^{\circ}$ iken üçgensel ahşap çıkıntı daha basık olduğundan üçgenler arasındaki düzlükte yerelleşmiş sadece bir adet yüzey bandı gözlenmektedir. Bu band, yaklaşık olarak $500 \mathrm{~Hz}$ 'e kadar olan frekanslarda hava çizgisine çok yakın seyretmekte olup bandın kiplerinin hava kiplerinden ayrıştırılması oldukça zordur. Buna karşın bandın tepe frekansı olan 652 Hz'e doğru band hava çizgisinden ayrılırken yüzey kipleri daha belirgin olarak ortaya çıkmaktadır. Bandın tepe frekansı etrafında (ya da $\mathrm{k}_{\mathrm{x}} \pi / a$ 'ya yaklaşırken) düzleşmesi şiddetli Bragg saçılmalarından kaynaklanmaktadır [22]. Şekil 2(a) incelendiğinde $\alpha$ azaldıkça yüzey bandının hava çizgisinden daha geniş frekans aralıklarında ayrıștığı ve tepe frekansının daha düşük değerlere kaydığı gözlenmektedir. Örneğin $\alpha=60^{\circ}$ iken yüzey bandının tepe frekansı $f=553$ $\mathrm{Hz}$ olmaktadır. Daha düșük tepe açılarında ise ikinci bir yüzey bandı ortaya çıkmaktadır.

$\alpha=60^{\circ}$ fononik kristalin $k_{x}=\pi / \mathrm{a}$ noktasındaki kip profili Şekil 2(b)'de verilmiştir. Burada solda görülen kip üçgensel bölgeler arasındaki düzlüğe ve biraz da beton içerisine yerelleşmiş yüzey kipidir. Fononik kristalle ses dalgalarının duvardan yansımasının engellenmesi bu yüzey kipinin uyarılması 
ile sağlanmaktadır. Buna karşın Şekil 2(b)'de sağda görülen kip hava çizgisi üzerinde kalan bir hava kipini göstermekte olup yüzey kipi değildir. Şekil 2(b)'de gösterilmemiş olmasına rağmen $\alpha>60^{\circ}$ için birinci yüzey bandının üzerinde görülen daha düz ikinci bir yüzey bandı üçgensel bölge içerisindeki hava boşluğunda yerelleşmiş yüzey kiplerine karşllık gelmektedir. Komşu birim hücreler arasında bu kiplerin etkileşimi zayıf olduğundan çalışmada bu tür kipler göz önünde bulundurulmamıștır. Ancak benzer fononik kristal yapılarda bu tür kiplerin varlı̆ğ sıvı ve gaz algılayıcıları gibi uygulamalar için oldukça uygundur [26, 27]. Band yapisı hesaplarında $t<15 \mathrm{~mm}$ iken ikinci yüzey bandının her $\alpha$ değerinde ortaya çıktığı gözlenmiştir. $\mathrm{Bu}$ durumda, algılayıcı uygulamaları için ince levha türü kaplamalar kullanılarak kip etkileşimlerinin artırılmasının sağlanması daha uygun olacağı görülmüş olur.

Yalın ve $a=25 \mathrm{~cm}, t=15 \mathrm{~mm}, \alpha=60^{\circ}$ olan bir fononik kristal içeren beton duvardan değişik frekanslarda $\theta=10^{\circ}$ geliş açısında gelen dalgaların yüzeyle etkileşimi ve yansıma davranışlarının durağan FEM simülasyon sonuçları Şekil 3'te verilmiștir. Burada $\theta$ dalganın yüzey ile yaptığı açı olarak tanımlanmıştır. Şekil 3'te kaynak genişliği ise oldukça uzaktaki noktasal bir kaynağa mümkün olduğunca benzeşim sağlamak için $w_{s r c}=3 a$ olarak seçilmiştir [24, 25]. Kaynaktan çıkan dalgalar, $p(\mathbf{r}, t)=p_{0} \mathrm{e}^{-\mathrm{i}(\mathbf{k} . \mathbf{r}-\omega t)}$ ile ifade edilen düzlem dalgalardır.
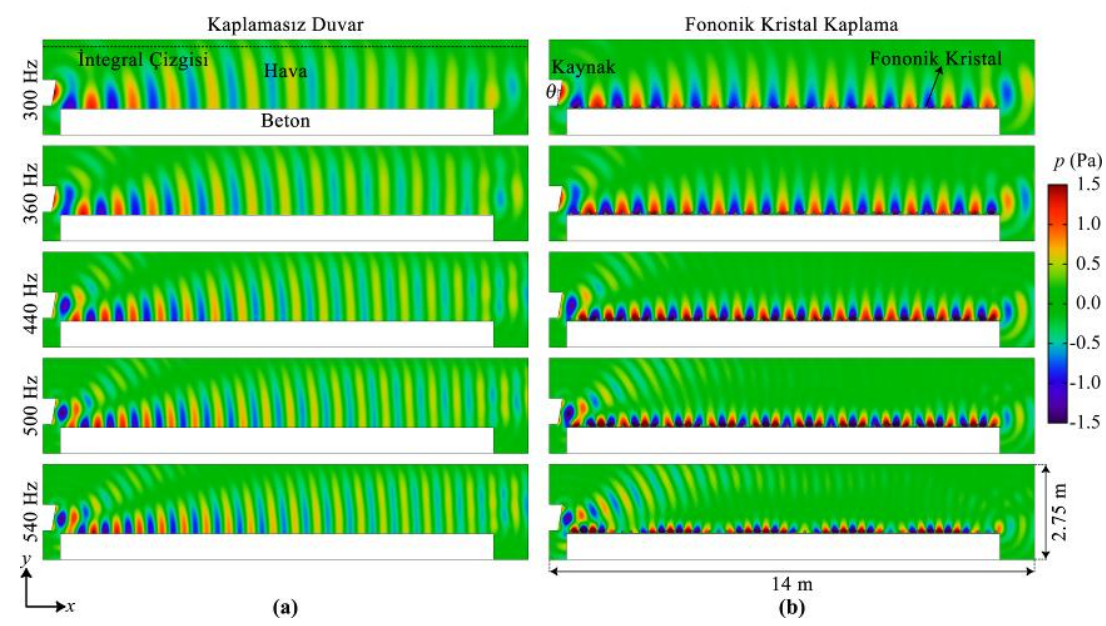

Şekil 3. Değișik frekanslardaki akustik dalgaların $\theta=10^{\circ}$ açı ile (a) yalın beton ve bir boyutlu fononik kristal içeren (b) duvara gelmesi sonucu davranıșlarının FEM simülasyon sonuçları.

Şekil 3(a)'da yalın beton duvara gelen dalgaların bir kısmının yüzeyden yansırken bir kısmının da yüzey boyunca ilerlediği görülmektedir. Ancak, ilerleyen dalgalar sinırlı kaynak boyutu nedeniyle kırınıma uğrayarak genişlemekte ve akustik enerji, hava ortamına doğru dağılmaktadır. Bu durumda, örneğin bir konser salonunda duvara yakın dinleyiciler hem doğrudan kaynaktan gelen hem de duvardan saçllan ses ekosunu duyacaklarından rahatsız olacaklardır.

Şekil 3(b)'de bir boyutlu fononik kristal kaplamanın yerleştirilmesi ile sesin duvardan saçılma karakteristiğinin önemli ölçüde değiştiği görülmektedir. $300 \mathrm{~Hz}$ ile $540 \mathrm{~Hz}$ arasindaki tüm frekanslarda yüzey kipinin uyarılıp 
akustik enerjinin yoğunluklu olarak yüzey boyunca kılavuzlandığı net olarak görülmektedir. Şekil 3(b)'de sesin duvardan yansıyan bileșeni de olmasına rağmen yansımanın önemli ölçüde azaldığı aşağıdaki tartışmalarla ortaya konulmuştur.

Ayrıca Şekil 3(b)'de, frekans arttıkça dalga boyu azaldığından ve Şekil 2(a)'da ki bandın tepe frekansına yaklaşıldığından yüzeydeki yerelleșmenin, dolayısıyla ses yalıtımının arttı̆̆ görülmektedir. Şekil 3(b)'nin orta satırında yukarıda belirtilen $440 \mathrm{~Hz}$ frekansında akustik yalıtımın sağlandığı net olarak ortaya çıkmaktadır. Buna karşin en alt satırda $f=540 \mathrm{~Hz}$ frekansında yüzey dalgasının vuru davranışı sergilediği gözlenmektedir. $\mathrm{Bu}$ davranış Brillouin bölgesi sınırına yaklaştıkça yüzeyde birbirine zıt yönlü dalga vektörleri ile hareket eden diğer tüm bakımlardan özdeş yüzey dalgalarının uyarılması nedeniyle meydana gelmektedir $[22,24]$.

Şekil 3(b)'nin en üst satırında 'integral çizgisi' olarak adlandırılan yatay kesikli çizgi duvardan akustik enerjinin hava ortamına yansımasını hesaplamak için kullanılan varsayımsal çizgiye karşıllı gelmektedir. Duvarın yansitma karakteristiği bu çizgi üzerinde akustik şiddetin bir ölçüsü olan basınç alanının mutlak değerinin karesinin $\left(|p(x, y)|^{2}\right)$ integralinin alınması ile belirlenmiştir. Şekil 4'te fononik kristal kaplamanın çalışılan frekans bölgesinde yansıtıcılığı azalttığı net olarak görülmektedir.

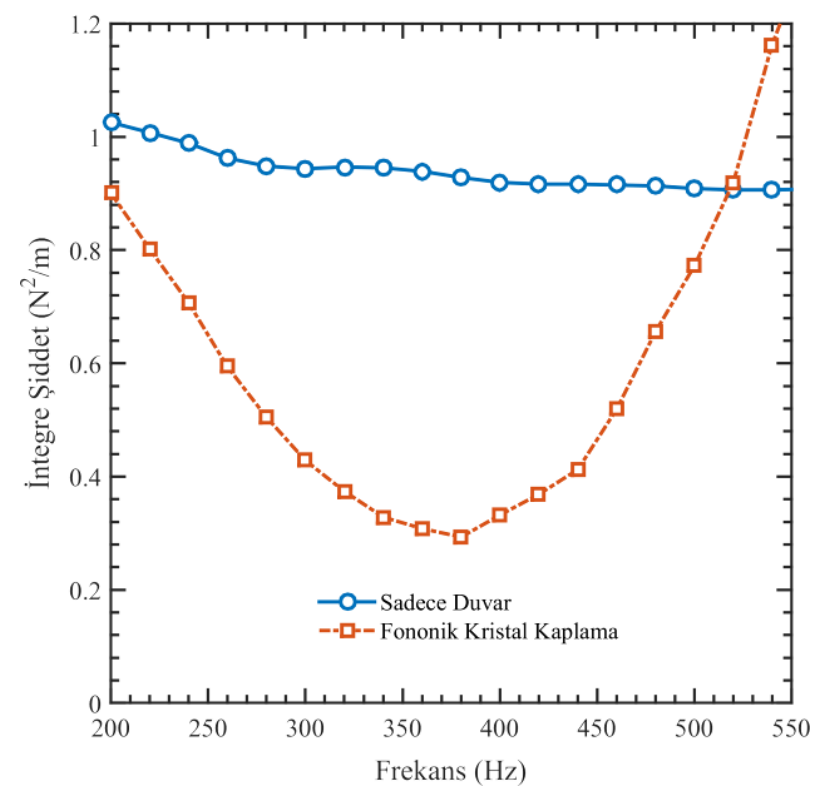

Şekil 4. $\theta=10^{\circ}$ geliş açısında akustik dalgaların sadece beton bloklardan oluşan ve 1 boyutlu fononik kristal içeren duvardan yansıma özelliklerinin frekansa bağlılığı.

Fononik kristal $f=440 \mathrm{~Hz}$ için optimize edildiğinden, fononik kristalle kaplı duvarın yansıtıcılığı en çok bu frekans etrafında azaltılmaktadır. Örneğin $f=380 \mathrm{~Hz}$ iken fononik kristal kaplı duvarın yansitıcılığı yalın duvarın yansıtıcılığının yaklaşık olarak dörtte birine düşmektedir. Fononik kristal kaplı duvarda ilerleyen yüzey dalgası duvar köşesine akustik soğurucular konularak bertaraf edilebilir. Ayrıca ahşap üzerine ince soğurucu katmanlar kaplanarak ya da ahşap yerine gözenekli malzemeler 
kullanılarak ses yalıtımı etkinliği artırılabilir.

Fononik kristalin yüzey dalgalarının uyarılması ile yalnızca yüzeye Şekil 3(b)'deki gibi hemen hemen paralel gelen dalgaların değil, değişik geliş açıları ile gelen dalgaların da yalıtılması beklenir. $\mathrm{Bu}$ nedenle, $\theta$ değiştirilerek fononik kristal kaplı duvarın yansıtıcılığının nasıl değiştiği durağan FEM analizleri ile incelenmiștir. Şekil $5^{\prime}$ te $\theta, 5^{\circ}$ ile $35^{\circ}$ arasında değiştirildiğinde elde edilen FEM simülasyon sonuçları gösterilmiştir. Burada, $f=440 \mathrm{~Hz}$ iken $\theta=30^{\circ}$ geliş açısına kadar yüzey dalgalarının uyarılıp fononik kristal yüzeyi boyunca kılavuzlandığı açıkça görülmektedir. Ancak, daha büyük geliş açllarında yüzey dalgalarının uyarılması havadan gelen dalgaların ve yüzey dalgalarının dalga vektörleri eşleşemediği için mümkün olmamaktadır. Şekil 5 'te geliş açısı arttıkça yansıyan bileșenin arttığı da görülmektedir. $\mathrm{Bu}$ durumda, konser salonu gibi ortamlarının yanal duvarlarının ve tavanının fononik kristal ile kaplanmasının daha iyi ses yalıtımı sağlayacağı ortaya çıkmaktadır.
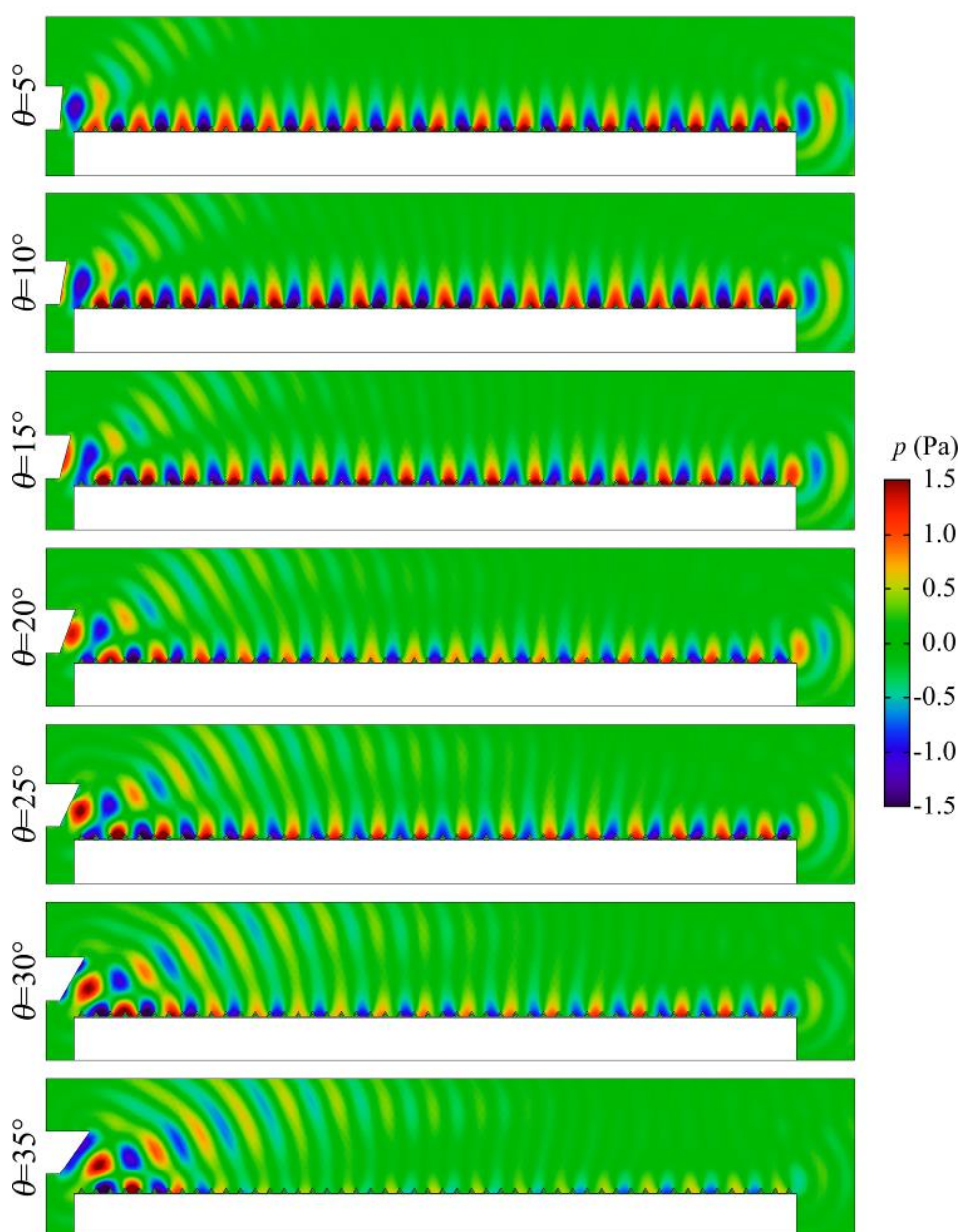

Şekil 5. $f=440 \mathrm{~Hz}$ frekansındaki akustik dalganın farklı geliş açılarına göre bir boyutlu fononik kristal kaplı duvar ile etkileşiminin FEM simülasyon sonuçları. 
Örneğin bir çalıșmada, iki farklı konser salonunun duvar kaplamalarının akustik soğurum özelliği farklı frekans bandlarının $1 / 1$ ve $1 / 3$ oktav genişliklerinde incelenmiştir [30]. Örneğin, $250 \mathrm{~Hz}$ merkez frekansının 1/1 oktav genişliğindeki bandı için, Münih'teki Fubertssaal in Schloss Nymphenburg'de ses soğurum katsayısı $(\alpha)$ bu frekans bandında 30 mm kalınlığında plaster kaplamalar için 0.123 iken, Japonya'daki Mitaka konser salonunun $33 \quad \mathrm{~mm}$ kalınlığındaki ağır alçı taşı kaplamaları için 0.097 olarak ölçülmüştür [30]. Bu çalışmada ise Şekil 4'teki veriler kullanılarak, fononik kristal kaplandığında $250 \mathrm{~Hz}$ frekansında 0.35 ve bu frekansin $1 / 1$ oktav genişliğinde ortalama olarak $\alpha=0.47$ hesaplanmış olup daha ince ahşapla periyodik kaplamanın ses soğurum özelliğini önemli ölçüde geliştirdiği belirlenmiştir

\section{Tartışma ve Sonuç}

Sonuç olarak, duyulabilir ses bölgesinde özellikle düşük frekanslarda beton duvarların yüzeylerinin periyodik üçgensel çıkıntılar içeren ahşap kaplamadan oluşan bir boyutlu fononik kristal ile kaplamanın önemli ölçüde ses yalıtımı sağladığı gösterilmiştir. Fononik kristalin üçgensel çıkıntıları arasında yerelleşmiş yüzey kiplerinin uyarılması ve yüzey boyunca kılavuzlanması ile akustik enerjinin duvardan yansıması ve saçılması önemli ölçüde azaltılabilmektedir. Hava ile beton duvar arakesitindeki yüzey kipleri, kendilerini band yapısında havanın dağılım eğrisi altında kalan ve Brillouin bölgesi sınırlarına yaklaşıldıkça hava çizgisinden ayrılan yüzey bandlarında göstermektedir. Yüzeye gelen düzlemsel dalgaların yüzey ile $30^{\circ}$ ve altında açı yaptıklarında kllavuzlanabildikleri görülmüștür. $\mathrm{Bu}$ durumda sahne içeren ortamlarda özellikle yanal duvarların ve tavanın fononik kristal ile kaplanmasının akustik yalıtımı önemli ölçüde artıracağı ön görülmüștür.

\section{Teşekkür}

FEM band yapısı hesaplarında ve simülasyonlarda hesaplama sisteminin ve COMSOL MultPhysics 4.3 yazılımının kullanımına izin verdiği için İnönü Üniversitesi Eğitim Fakültesi Bilgisayar ve Öğretim Teknolojileri Öğretmenliği Bölümü Öğretim Üyesi Doç. Dr. Olgun Adem KAYA'ya şükranlarımı sunarım.

\section{Kaynakça}

[1] Mehta, M., Johnson, J., Rocafort, J. 1999. Architectural acoustics: Principles and Design, Prentice Hall.

[2] Maldovan, M. 2013. Sound and heat revolutions in phononics, Nature, Cilt. 503, No. 7475, s. 209-217. Doi: $10.1038 /$ nature 12608

[3] Kushwaha, M.S., Halevi, P., Dobrzynski, L., Djafari-Rouhani, B. 1993. Acoustic band structure of periodic elastic composites, Physical Review Letters, Cilt. 71, No. 13, s. $2022 . \quad$ DOI: https://doi.org/10.1103/PhysRevLett. 71.2022

[4] Kushwaha, M.S., Halevi, P., Martinez, G., Dobrzynski, L., DjafariRouhani, B. 1994. Theory of acoustic band structure of periodic elastic composites, Physical Review B, Cilt. 49, No. 4, s.2313. DOI: https://doi.org/10.1103/PhysRevB.49 .2313

[5] Sainidou, R., Stefanou, N., Modinos, A. 2002. Formation of absolute 
frequency gaps in three-dimensional solid phononic crystals, Physical Review B, Cilt. 66, No. 21, s. 212301. DOI:

https://doi.org/10.1103/PhysRevB.66 .212301

[6] Vasseur, J., Deymier, P.A., DjafariRouhani, B., Pennec, Y., HladkyHennion, A. 2008. Absolute forbidden bands and waveguiding in twodimensional phononic crystal plates, Physical Review B, Cilt. 77, No.8, s. 085415. DOI: https://doi.org/10.1103/PhysRevB.77 .085415

[7] Martínez-Sala, R., Rubio, C., GarcíaRaffi, L. M., Sánchez-Pérez, J. V., Sánchez-Pérez, E.A., Llinares, J. 2006. Control of noise by trees arranged like sonic crystals, Journal of Sound and Vibration, Cilt. 291, No. 1, s. 100-106. DOI:

http://dx.doi.org/10.1016/j.jsv.2005. 05.030

[8] Wu, T.T., Huang, Z.G., Tsai, T.C., Wu, T.C. 2008. Evidence of complete band gap and resonances in a plate with periodic stubbed surface, Applied Physics Letters, Cilt. 93, No. 11, s. 111902. DOI: $10.1063 / 1.2970992$

[9] Tanaka, Y., Tomoyasu, Y., Tamura, S.I. 2000. Band structure of acoustic waves in phononic lattices: Twodimensional composites with large acoustic mismatch, Physical Review B, Cilt. 62, No. 11, s. 7387. DOI: https://doi.org/10.1103/PhysRevB.62 .7387

[10] Gorishnyy, T., Ullal, C.K., Maldovan, M., Fytas, G., Thomas, E. 2005. Hypersonic phononic crystals, Physical Review Letters, Cilt. 94, No. 11, s. $115501 . \quad$ DOI: https://doi.org/10.1103/PhysRevLett. 94.115501

[11] Gomopoulos, N., Maschke, D., Koh, C., Thomas, E., Tremel, W., Butt, H.J., Fytas, G. 2010. One-dimensional hypersonic phononic crystals, Nano Letters, Cilt. 10, No. 3, s. 980-984. DOI: $10.1021 / \mathrm{nl} 903959 \mathrm{r}$

[12] Maldovan M, Narrow lowfrequency spectrum and heat management by thermocrystals, Physical Review Letters, Cilt. 110, No. 2, 2013, s.025902.

[13] Palucka T, Nano Focus: Theoretical thermocrystals control heat like sound, MRS Bulletin, Cilt. 38, No. 03, 2013, s.200.

[14] Lacatena, V., Haras, M., Robillard. J. F., Monfray, S., Skotnicki, T., Dubois, E. 2015. Toward quantitative modeling of silicon phononic thermocrystals, Applied Physics Letters, Cilt. 106, No. 11, s.114104. DOI:

http://dx.doi.org/10.1063/1.4915619

[15] Miyashita, T., Inoue, C. 2001. Numerical investigations of transmission and waveguide properties of sonic crystals by finitedifference time-domain method, Japanese Journal of Applied Physics, Cilt. 40, No. 5S, s.3488. DOI: http://dx.doi.org/10.1143/JJAP.40.34 88

[16] Miyashita, T. 2005. Sonic crystals and sonic wave-guides, Measurement Science and Technology, Cilt. 16, No. 5, s. R47. DOI: http://dx.doi.org/10.1088/09570233/16/5/R01

[17] Hsiao, F.L., Khelif, A., Moubchir, H., Choujaa, A., Chen, C.C., Laude, V. 2007. Waveguiding inside the complete band gap of a phononic crystal slab, Physical Review E, Cilt. 76, No. 5, s.056601. DOI: https://doi.org/10.1103/PhysRevE.76 .056601

[18] Vasseur, J., Hladky-Hennion, A. C., Djafari-Rouhani, B., Duval, F., Dubus, B., Pennec, Y., Deymier, P.A. 2007. Waveguiding in two-dimensional 
piezoelectric phononic crystal plates, Journal of Applied Physics, Cilt. 101, No. 11, s.114904. DOI: http://dx.doi.org/10.1063/1.2740352

[19] Khelif, A., Choujaa, A., Benchabane, S., Djafari-Rouhani, B., Laude, V. 2004. Guiding and bending of acoustic waves in highly confined phononic crystal waveguides, Applied Physics Letters, Cilt. 84, No. 22, s.4400-4402. DOI: http://dx.doi.org/10.1063/1.1757642

[20] Wu, F., Hou, Z., Liu, Z., Liu, Y. 2001. Point defect states in two-dimensional phononic crystals, Physics Letters A, Cilt. 292, No. 3, s.198-202. DOI: http://dx.doi.org/10.1016/S03759601(01)00800-3

[21] Wu, F., Liu, Z., Liu, Y. 2004. Splitting and tuning characteristics of the point defect modes in twodimensional phononic crystals, Physical Review E, Cilt. 69, No. 6, s.066609. DOI: 10.1103/PhysRevE.69.066609

[22] Zhao, D., Liu, Z., Qiu, C., He, Z., Cai, F., Ke, M. 2007. Surface acoustic waves in two-dimensional phononic crystals: Dispersion relation and the eigenfield distribution of surface modes, Physical Review B, Cilt. 76, No. 14, s.144301. DOI:

https://doi.org/10.1103/PhysRevB.76 .144301

[23] Jia, H., Ke, M., He, Z., Peng, S., Liu, G., Mei, X., Liu, Z. 2009. Experimental demonstration of surface acoustic waves in two-dimensional phononic crystals with fluid background, Journal of Applied Physics, Cilt. 106, No. 4, s.044512. DOI: http://dx.doi.org/10.1063/1.3200964

[24] Cicek, A., Gungor, T., Kaya, O.A., Ulug, B. 2015. Guiding airborne sound through surface modes of a twodimensional phononic crystal, Journal of Physics D: Applied Physics, Cilt. 48, No. 23, s.235303. DOI: http://dx.doi.org/10.1088/0022$3727 / 48 / 23 / 235303$

[25] Cicek, A., Salman, A., Kaya, O.A., Ulug, B. 2015. Sharp bends of phononic crystal surface modes, Journal of Physics: Condensed Matter, Cilt. 27, No. 47, s.475003. DOI: 10.1088/0953-8984/27/47/475003

[26] Cicek, A., Salman, A., Kaya, O.A., Ulug, B. 2016. Phononic crystal surface mode coupling and its use in acoustic Doppler velocimetry, Ultrasonics, Cilt. 65, s.78-86. DOI: 10.1016/j.ultras.2015.10.017

[27] Cicek, A., Salman, A., Kaya, O.A., Ulug, B. 2015. Evanescent coupling between surface and linear-defect guided modes in phononic crystals, Journal of Physics D: Applied Physics, Cilt. 49, No. 3, s.035103. DOI: http://dx.doi.org/10.1088/0022-

3727/49/3/035103

[28] Laude, V., Wilm, M., Benchabane, S., Khelif, A. 2005. Full band gap for surface acoustic waves in a piezoelectric phononic crystal, Physical Review E, Cilt. 71, No. 3, s.036607. DOI: https://doi.org/10.1103/PhysRevE.71 .036607

[29] Salman, A., Kaya, O.A., Cicek, A., Ulug, B. 2015. Low-concentration liquid sensing by an acoustic MachZehnder interferometer in a twodimensional phononic crystal, Journal of Physics D: Applied Physics, Cilt. 48, No. 25, s.255301. DOI: http://dx.doi.org/10.1088/0022$\underline{3727 / 48 / 25 / 255301}$

[30] Beranek, L. L. ve Hidaka, T. 1998. Sound absorption in concert halls by seats, occupied and unoccupied, and by the hall's interior surfaces, The Journal of the Acoustical Society of America, Cilt. 104, s.3169. DOI: http://dx.doi.org/10.1121/1.423957 